\title{
Selection of the Technological Ceramic Layer Thickness in an HPDC Machine Plunger in the Aspect of its Strength
}

\author{
Jacek Jankowski ${ }^{*}$, Dariusz Kołakowski², Bogusław Pisarek² \\ 1 Department of Strength of Materials, Lodz University of Technology, Stefanowskiego 1/15, 90-924 Lodz, \\ Poland \\ 2 Department of Materials Engineering and Production Systems, Lodz University of Technology, Stefanowskiego \\ 1/15, 90-924 Łódź, Poland \\ * Corresponding author's e-mail: jacek.jankowski@p.lodz.pl
}

\begin{abstract}
A way of selecting the ceramic coating thickness concerning the axially symmetrical thermal stresses in a casting machine plunger with a horizontal shot sleeve was discussed. Application of a technological ceramic outer layer in the plunger enhances its tribological properties. The condition that stresses in tension in the outer ceramic layer are lower than the tensile strength was proposed as a selection criterion.
\end{abstract}

Keywords: plungers, HPDC machine, thermal stresses, axially symmetrical thermal stress state

\section{INTRODUCTION}

The pressure casting of aluminium and copper alloys is the primary technology in the manufacturing products for household appliances, automotive industry, etc. A detailed analysis of the technological process during pressure casting is very complex due to the mechanical and thermal fatigue, creeping, erosion, cavitation, dissolution of mould and metal components, adhesion. In order to meet the requirements imposed by the end-users, the producers of pressure casts should improve their products, lower the costs and increase the wear life of the pressure elements in HPDC machines.

A thermal stress state in the high pressure die casting (HPDC) machine plunger with a horizontal shot sleeve has been dealt with. One of the reasons for the premature destruction of plungers involves the thermal stresses generated by the cyclic process during their operation.

In the fixed production cycle of pressure casting, after the start-up phase, it can be assumed that the thermal stresses do not alter during one operation cycle due to the high heat capacity of the mould.
In [4] devoted to the analysis of the mechanical and thermal stress state in a plunger of the cold-chamber HPDC machine with a horizontal shot sleeve, the temperature distributions in the shot sleeve were discussed based on $[6,7]$. The stress state was considered on the assumption of a homogenous temperature field in the plunger surroundings. For comparison, the calculations were conducted for four different materials used for cold-chamber HPDC machine plungers, namely: grey Pearlic cast iron, high silicon bronze, beryllium bronze and aluminium-iron-nickel bronze which is the source alloy for the newly developed complex bronzes of high wear resistance and enhanced strength.

In [5], the distribution of the stress state components for the non-homogenous stationary temperature field, i.e., for the conditions close to actual operating conditions of the plunger $[6,7]$, was investigated. The whole cycle, including the time of filling the sleeve with a molten metal lasts less than 3 minutes, whereas the plunger loading is shorter than $60 \mathrm{~s}$.

In the case of the HPDC machine plunger, the pressing pressure is a compressive axial load 
equal even up to $100 \mathrm{MPa}$, whereas the maximal load is equal to zero during filling the sleeve. From the viewpoint of fatigue resistance, it is a negative pulsating cycle.

In [5], it was shown that the maximal mechanical and thermal stresses for the flat stress state and the $3 \mathrm{D}$ stress state differ by $12 \%$ at most from the maximal stresses for the axially symmetrical thermal state and the 3D stress state at the same maximal temperature of the plunger on its outer surface and a constant temperature, forced with a cooling agent cycle, inside the plunger.

The reason for the premature wear of a plunger during the technological process lies in a superimposition of the thermal internal stresses with the stresses generated cyclically by the external forces during the plunger operation. In order to increase the plunger life, a technological outer layer can be applied. In this study, a ceramic $\mathrm{Al}_{2} \mathrm{O}_{3}$ layer was proposed due to its mechanical and tribological properties. Ceramic coatings are characterized by high abrasion resistance, high mechanical resistance, and resistance to high temperatures (even up to $1700^{\circ} \mathrm{C}$ ), chemical corrosion and erosion. Owing to these numerous properties, the elements made of alumina $\mathrm{Al}_{2} \mathrm{O}_{3}$ are ideally suited for operate in hazardous environments. Ceramic coatings are used in chemical, food and petrochemical industries, in environment protection, power generation, water and sewage management and many other branches of industry. Due to the application of these materials, it is possible to increase the service life and reliability of devices, to the elongate periods between overhauls, to decrease the energy losses and risks of environmental contamination. Their strength guarantees the longer operation of HPDC machines and devices without a necessity of frequent maintenance works and random shutdowns, which follows from a significant increase in the tribological properties.

The technological oxide coatings obtained with an electrolytic method on aluminium alloys are widely used in kinematic sliding couplings of machine elements of the piston-cylinder type. In the case a polymer mate element is applied, a sliding coupling is used in kinematical pairs under the technical dry friction conditions. The ceramic coatings based on alumina $\mathrm{Al}_{2} \mathrm{O}_{3}$ are broadly used in the industry. This material is characterized by high hardness, wear resistance, resistance to corrosion that does not react with metals while being heated up to very high temperatures. Very good tribological properties are exhibited by the plasma-sprayed coatings based on powdered $\mathrm{Al}_{2} \mathrm{O}_{3}$ and powdered $\mathrm{Al}_{2} \mathrm{O}_{3}$-B containing diffused boron. Its diffusion reduces wear almost by half when a lubricant is used and more than 5 times under the conditions of dry friction when compared to a coating including $\mathrm{Al}_{2} \mathrm{O}_{3}$ solely.

Application of the technological ceramic $\mathrm{Al}_{2} \mathrm{O}_{3}$ outer coating results in a decrease in the temperature acting on the plunger outer surface and an improvement in the tribological properties in the HPDC machine plunger-cylinder kinematic pair.

The $\mathrm{Al}_{2} \mathrm{O}_{3}$ coating is characterised by the tensile strength $R_{m}$ and the compression strength $R_{c}$ that differ considerably, as even $R_{c} / R_{m} \approx 10$ [11].

The tensile stresses occur on the outer surface of a one-layer plunger, whereas the compression stresses are present on the inner surface [4,5]. On both surfaces, the radial stresses are equal to zero. Moreover, the axial stresses are neglected in the study as $\sigma_{z}=0$. For a two-layer sleeve, stresses should be lower than the tensile strength $R_{m}$ on the technological ceramic outer layer due to its durability. Thus, an $\mathrm{Al}_{2} \mathrm{O}_{3}$ layer of adequate thickness should be deposited. This is the target of the present study.

A methodology for selecting the thickness of the ceramic $\mathrm{Al}_{2} \mathrm{O}_{3}$ outer coating deposited on a plunger made of the CuAl10Fe5Ni5 aluminiumiron-nickel bronze was proposed. The ceramic $\mathrm{Al}_{2} \mathrm{O}_{3}$ coatings are characterized by the mechani$\mathrm{cal}$ properties that differ much depending on the way of their deposition and manufacturing. Variability in a wide range of allowable stresses in tension was considered in this study. As a selection criterion, it was assumed that the stresses in the coating have to be lower than the allowable stresses in tension. The stress distributions thus determined should be taken into account in the selection criterion of the technological outer layer and possibly in further technological applications.

The analysis of the plunger/sleeve operation presented here is based on a representation of the actual die casting process that takes place with a Buehler HPDC machine in the WIFAMA-PREXER company located in Lodz [4].

\section{FORMULATION OF THE PROBLEM}

In order to derive the relationships describing distributions of temperatures, mechanical and thermal stresses for the axially symmetrical 
stationary problem, the following assumptions were taken $[2,4,5,9]$ :

1. Kelvin's phenomenon is neglected (an increase in temperature is accompanied by material strain);

2. There is no heat source (i.e., $Q=0$ );

3. A temperature field is determined independently of stresses and strains from the classical equation of conductivity, that is to say, for the stationary problem;

4. A temperature curve was assumed for the flat problem and it does not depend on the coordinate $\mathrm{z}$ along the sleeve axial direction;

5. The thermal stresses are caused by the timeconstant temperature field;

6. The elastic and thermal properties of the pipe material do not depend on temperature;

An analysis of the thermal stresses in an HPDC machine plunger made of the aluminiumiron-nickel bronze was carried out. According to the conclusions following from [5], a simplified axially symmetrical stress state [4] can be assumed with sufficient accuracy (up to $12 \%$ ) in comparison to the flat stress state, which corresponds better to the actual stress state in the plunger. A simplified model considerably facilitates the solution and an analysis of the problem.

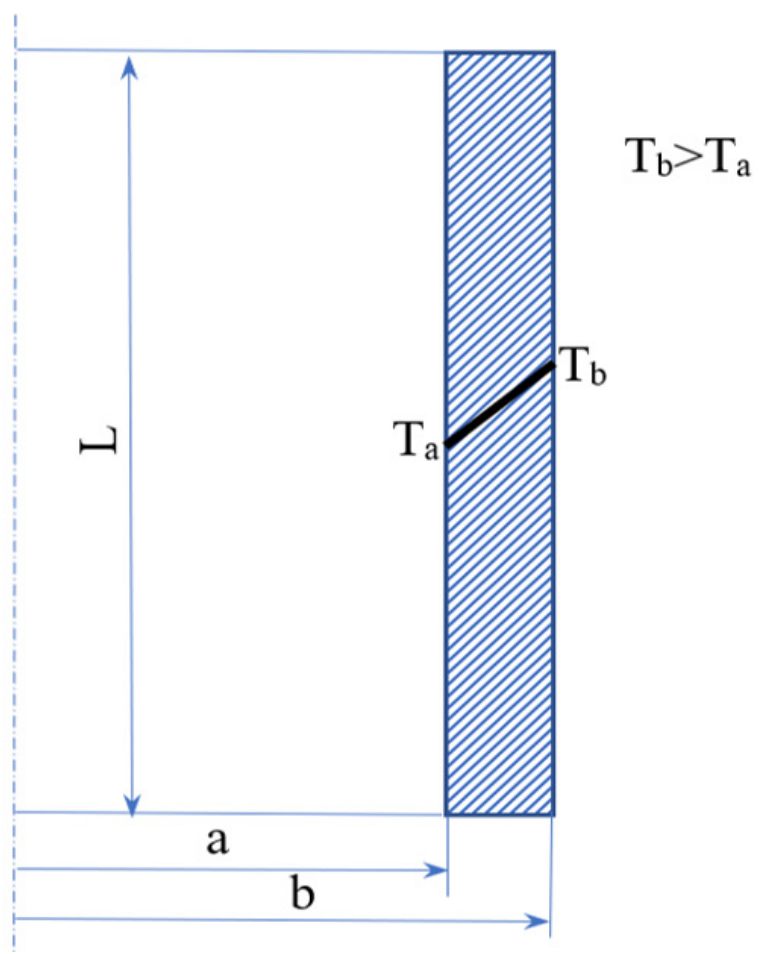

Fig. 1. Temperature distribution in the homogenous piston
The starting point is a homogenous plunger made of the CuAl10Fe5Ni5 bronze. The outer temperature of the plunger is higher than the inner one. This is a reference model (Fig. 1). The case in which a top technological ceramic $\mathrm{Al}_{2} \mathrm{O}_{3}$ coating was deposited on the plunger outer surface to improve the tribological properties was considered. In the considerations, the outer and inner diameters of the plunger were constant. The thickness of the ceramic layer caused a decrease in the bronze sleeve outer diameter by this thickness thus (Fig. 2).

For the bronze sleeve as well as for the cylindrical ceramic ring, the same model, i.e., the equations for thick-walled sleeves, were assumed. The properties of the bronze sleeve and the $\mathrm{Al}_{2} \mathrm{O}_{3}$ coating are listed in Table $1[4,5]$.

In Appendix I, a solution to the heat transfer problem in a two-layer cylindrical plunger/ sleeve was presented. It allows one to determine the temperature at the interface of the layers and to consider the sleeve and the ring separately for the assumed temperatures inside and outside the sleeve. Next, the stress state components caused by the thermal load were determined in the bronze sleeve and the ceramic ring. In Figure 3, the sleeve and the ring after their separation are presented, and then their interaction is marked with

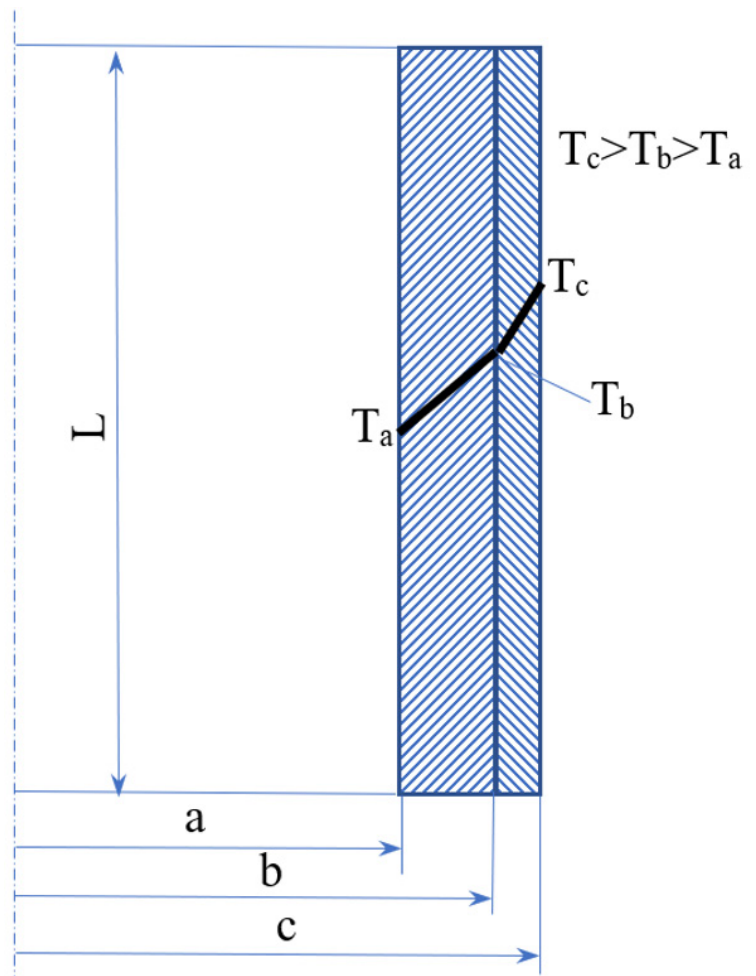

Fig. 2. Temperature distribution in the piston with a ceramic outer coating (i.e., ring) 
the load $q$. The sleeve strain on the outer surface has to be equal to the strain on the inner surface of the plunger.

In Appendix II, a problem for a single thickwall cylindrical sleeve subject to thermal load (Fig. 3a) is solved. In order to complete the solution, integration constants should be determined from the boundary conditions.

For the reference model (Fig. 1), i.e., at a lack of the ceramic ring, integration constants were determined from the following boundary conditions [4]:

$$
\sigma_{r}(r=a)=\sigma_{r}(r=b)=0
$$

However, as regards the case presented in Fig. 3a, it should be assumed additionally that $q=0$. For a one-layer bronze sleeve, stress components are expressed with the relationships [4]:

a)

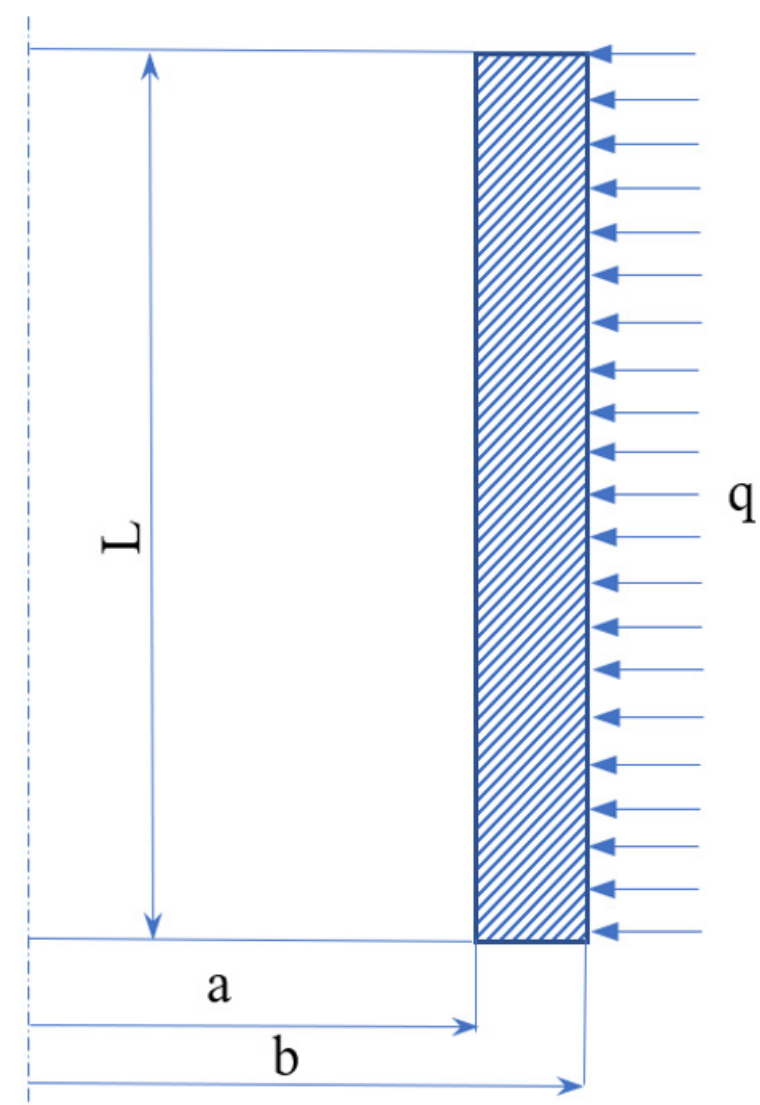

$\sigma_{r}=-\frac{E \alpha\left(T_{a}-T_{b}\right)}{2}\left[\frac{\ln (b / r)}{\ln (b / a)}-\frac{\left(b^{2} / r^{2}-1\right)}{\left(b^{2} / a^{2}-1\right)}\right]$

$\sigma_{t}=-\frac{E \alpha\left(T_{a}-T_{b}\right)}{2}\left[\frac{\ln (b / r)-1}{\ln (b / a)}+\frac{\left(b^{2} / r^{2}+1\right)}{\left(b^{2} / a^{2}-1\right)}\right]$

In the case of a two-layer plunger, the following index notations were assumed, namely: 1 - bronze sleeve, 2 - ceramic ring. According to Fig. 3a, we have the following boundary conditions for the sleeve:

$$
\sigma_{r 1}(r=a)=0 \quad \sigma_{r 1}(r=b)=-q
$$

whereas for the ceramic ring (Fig. 3b), correspondingly:

$$
\sigma_{r 2}(r=b)=-q \quad \sigma_{r 2}(r=c)=0
$$

Thus, a strain compatibility condition holds at the interface of these two layers (Fig. 2), that is to say:

b)

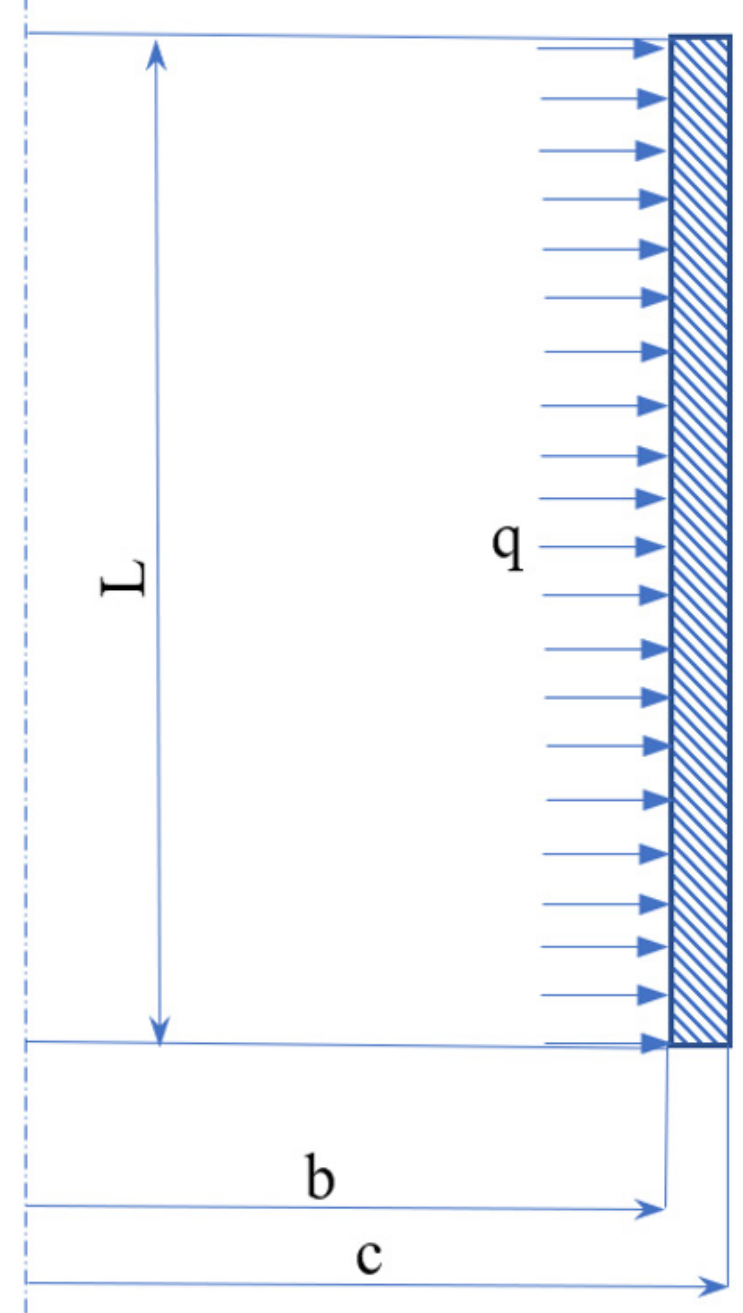

Fig. 3a. Sleeve detached from the ring after mutual interaction

Fig. 3b. Ring detached from the sleeve after mutual interaction 


$$
u_{r 1}(r=b)=u_{r 2}(r=b)
$$

The above-mentioned boundary conditions allow one to explicitly determine the stress components in the plunger and the ring. It should be reminded that for the ring, a thick-wall sleeve model is assumed (2D model). In the theory of strength of materials, a simplified model is used for thin-walled rings, on the assumption that a unidirectional stress state (1D) (i.e., circumferential stresses are accounted for, whereas radial stresses are neglected) exists there.

The stresses $\sigma_{r}, \sigma_{t}$ are principal stresses for the axially symmetrical stress state, which means that it was assumed that axial (the so-called longitudinal) stresses are neglected, i.e., $\sigma_{z}=0$.

\section{ANALYSIS OF THE RESULTS}

In order to conduct a detailed analysis, a special code was written, the basic assumptions and formulas of which are presented in this study. The code was used to determine the stress state components in a two-layer plunger.

Detailed calculations were carried out for the following input data referring to the actual conditions existing during the process on the working site of a Buehler HPDC machine located in the WIFAMA-PREXER company:

- Plunger outer temperature $\mathrm{T}_{\mathrm{b}}=300^{\circ} \mathrm{C}$;

- Plunger inner temperature $\mathrm{T}_{\mathrm{a}}=150^{\circ} \mathrm{C}$;

- Plunger outer diameter $\mathrm{D}=2 \mathrm{~b}=70 \mathrm{~mm}$;

- Plunger inner diameter $\mathrm{d}=2 \mathrm{a}=42 \mathrm{~mm}$;

It was assumed that the plunger was made of the aluminium-iron-nickel bronze [4,5] and an $\mathrm{Al}_{2} \mathrm{O}_{3}$ coating $[11,12]$ with material constants listed in Table 1.

Due to a high variability in the tensile strength of $\mathrm{Al}_{2} \mathrm{O}_{3}$, various thicknesses of the ceramic ring were considered, starting from its lack (the so-called reference model - Fig. 1) up to the thickness of $1 \mathrm{~mm}$, every $0.1 \mathrm{~mm}$ (Fig. 2), and for the thickness equal to $1.5 \mathrm{~mm}$ and $2.0 \mathrm{~mm}$. The stresses in tension in the ceramic ring could be thus determined and compared to the assumed strength of the ceramic coating.

First, in Table 2, the values of the circumferential stresses for the one-layer bronze sleeve (i.e., without a ceramic coating) on the inner and outer surface of the plunger and the equivalent stresses according to the $\mathrm{HMH}$ hypothesis (Appendix III) are listed. In these cases, the absolute values of the circumferential stresses are identical to the equivalent stresses because the radial stresses on the surfaces are equal to zero. The highest stresses in tension on the inner surface area equal to $156 \mathrm{MPa}$, whereas on the outer surface, the stresses in compression are the highest and they are equal to $111 \mathrm{MPa}$.

Next, the values of temperature at the interface of two surfaces, circumferential stresses for the radii: $r=a ; r=b ; r=c$ are given. Additionally, the equivalent $\mathrm{HMH}$ stresses for the ceramic ring at $r=b$ are listed because the radial stresses at the interface of the two layers are not equal to zero. As can be easily noticed, in the ceramic ring the circumferential stresses $\sigma_{t 2}$ are the stresses in tension and they are more than three times as high as the stresses $\sigma_{t 1}(\mathrm{r}=\mathrm{a})$. Along with an increase in the ring thickness (i.e., $\delta=r_{c}-r_{b}$ ), the values of all stresses decrease. For $r=b$, the stresses $\sigma_{t 2}$ and $\sigma_{\mathrm{HMH}_{2}}$ differ inconsiderably, which is following (A3.1), when the stresses $\sigma_{r 2}$ are insignificant.

Attention should be paid to the values of the stresses $\sigma_{t 2}(r=b)$ and $\sigma_{t 2}(r=c)$ for the 2D model. When the ring thickness $\delta$ is low (i.e., $\delta \leq 0.4 \mathrm{~mm}$, that is to say, for $\left.\mathrm{r}_{\mathrm{c}} / \mathrm{r}_{\mathrm{b}} \leq 1.01\right)$, then $\sigma_{t 2}(r=b) / \sigma_{t 2}(r=c) \leq 1$.1. In the theory of strength of materials, constant circumferential stresses along the radius thickness are assumed for thinwalled rings (1D model). Thus, when $\delta \leq 0.4 \mathrm{~mm}$, then the compatibility of both the models is good. With an increase in the plunger thickness $\delta$, the ratio $\sigma_{t 2}(r=b) / \sigma_{t 2}(r=c)$ grows and for $\delta=2 \mathrm{~mm}$, this ratio equals already 2.5 .

Although it can be assumed according to [11] that $R_{m}=260 \mathrm{MPa}$, then only if $\delta=2.0 \mathrm{~mm}$, the relationship $\sigma_{t_{2}} \approx \sigma_{H M H} \approx \mathrm{R}_{m}$ holds. An application of a thinner ceramic layer leads to its damage at the interface of the two layers. Thus,

Table 1. Assumed material data of the bronze plunger and the ceramic ring

\begin{tabular}{|c|c|c|c|c|c|c|}
\hline \multirow{2}{*}{ Index } & \multirow{2}{*}{ Materials } & $E$ & $v$ & $\alpha$ & $I$ & $R_{m}$ \\
\cline { 3 - 7 } & & $\mathrm{GPa}$ & - & $10^{-6} / \mathrm{K}$ & $\mathrm{W} /(\mathrm{m} \cdot \mathrm{K})$ & 41.9 \\
\hline 1 & $\mathrm{CuAl10Fe5Ni5}$ & 110 & 0.34 & 16.2 & 620 \\
\hline 2 & $\mathrm{Al}_{2} \mathrm{O}_{3}[11]$ & 370 & 0.22 & 7.6 & 26.0 & $260 /(70-665)[12]$ \\
\hline
\end{tabular}


Table 2. Stresses in the ceramic coating of the two-layer sleeve

\begin{tabular}{|c|c|c|c|c|c|c|}
\hline$r_{b}$ & $d=r_{c}-r_{b}$ & $s_{r 1}(r=a)$ & $T_{b}$ & $s_{t 2}(r=b)$ & $\mathrm{S}_{\mathrm{HMH} 2}(r=b)$ & $\mathrm{s}_{\mathrm{t} 2}(\mathrm{r}=\mathrm{c})$ \\
\hline$[\mathrm{mm}]$ & {$[\mathrm{mm}]$} & [MPa] & {$\left[{ }^{\circ} \mathrm{C}\right]$} & [MPa] & {$[\mathrm{MPa}]$} & [MPa] \\
\hline \multicolumn{7}{|c|}{ One-layer sleeve } \\
\hline 35.0 & 0.0 & 156 & 300 & -111 & 111 & - \\
\hline \multicolumn{7}{|c|}{ Two-layer-sleeve } \\
\hline 34.9 & 0.1 & 148 & 297.3 & 505 & 506 & 496 \\
\hline 34.8 & 0.2 & 141 & 294.6 & 487 & 489 & 469 \\
\hline 34.7 & 0.3 & 134 & 291.9 & 470 & 472 & 443 \\
\hline 34.6 & 0.4 & 128 & 289.2 & 453 & 455 & 418 \\
\hline 34.5 & 0.5 & 122 & 286.5 & 437 & 440 & 393 \\
\hline 34.4 & 0.6 & 116 & 283.8 & 421 & 425 & 369 \\
\hline 34.3 & 0.7 & 111 & 281.1 & 406 & 410 & 345 \\
\hline 34.2 & 0.8 & 106 & 278.7 & 392 & 397 & 324 \\
\hline 34.1 & 0.9 & 101 & 276.0 & 378 & 383 & 302 \\
\hline 34.0 & 1.0 & 96 & 273.3 & 364 & 369 & 291 \\
\hline 33.5 & 1.5 & 77 & 260.4 & 307 & 312 & 184 \\
\hline 33.0 & 2.0 & 63 & 247.8 & 260 & 265 & 102 \\
\hline
\end{tabular}

a ceramic layer of higher strength, e.g., as in [12] for $R_{m}<665 \mathrm{MPa}$, should be used. Then, if $\mathrm{R}_{m} \approx 600 \mathrm{MPa}, \delta=0.1 \mathrm{~mm}$, and further on, when $R_{m}^{m} \approx 500 \mathrm{MPa}-\delta=0.3 \mathrm{~mm}$, when $R_{m} \approx 450 \mathrm{MPa}-$ $\delta=0.5 \mathrm{~mm}$, and when $R_{m} \approx 400 \mathrm{MPa}-\delta=0.9 \mathrm{~mm}$, respectively.

In Figs. 4-8, plots of stress components as a function of the plunger radius for the reference model (i.e., a one-layer sleeve $(\delta=0.0 \mathrm{~mm}$ (Fig. 4) ) and a two-layer sleeve $(\delta=0.5 ; 1.0 ; 1.5$ and $2.0 \mathrm{~mm}$ (Figs. 5-8)) are presented. The diagrams were plotted to facilitate a comparison of stresses both in the bronze sleeve as well as in the ceramic ring. At the interface of two layers, there is a condition of displacement conformity, but not stress conformity, which is represented with a step-like alternation in stresses at the interface. The radial stresses do not exceed $17 \mathrm{MPa}$ for all the cases under analysis. For the one-layer sleeve, the stresses $\sigma_{r}$ are stresses in tension. On the other hand, for the two-layer sleeve, the stresses $\sigma_{r 1}$ in the bronze plunger (Fig. 3a) change their sign near the interface of the layers and are stresses in compression, whereas the stresses $\sigma_{r 2}$ in the ring are always stressed in compression and they attain their maximal value at the interface of both the layers.

\section{CONCLUSIONS}

A stress state analysis in two-layer plungers of the HPDC machines subject to thermal stationary loads for the axially symmetrical stress state, which follows from the conclusions provided in [5], was presented. The case when a technological ceramic outer coating is deposited to enhance the tribological properties was considered. As an example, a ceramic $\mathrm{Al}_{2} \mathrm{O}_{3}$ layer deposited on the CuA110Fe5Ni5 bronze

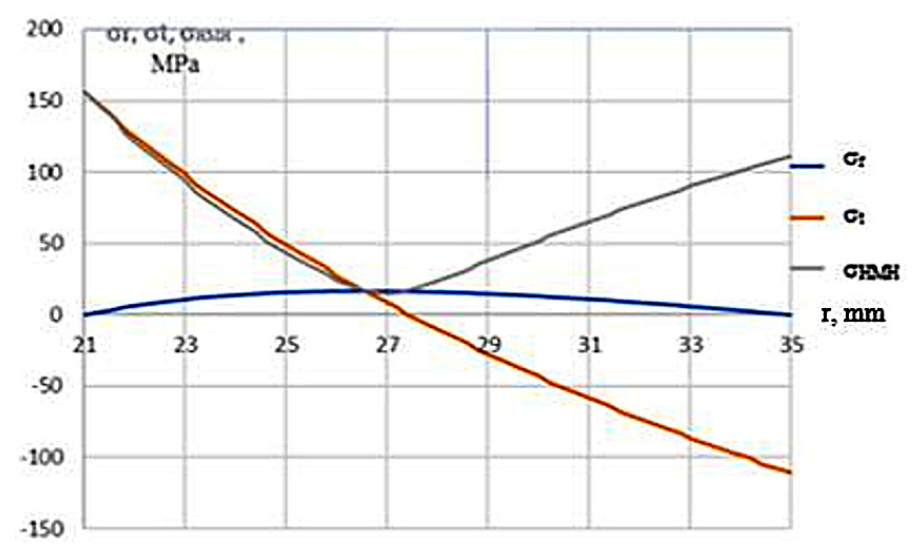

Fig. 4. Distributions of component stresses as a function of the radius $r$ for the homogenous piston (for $\delta=0$ ) 


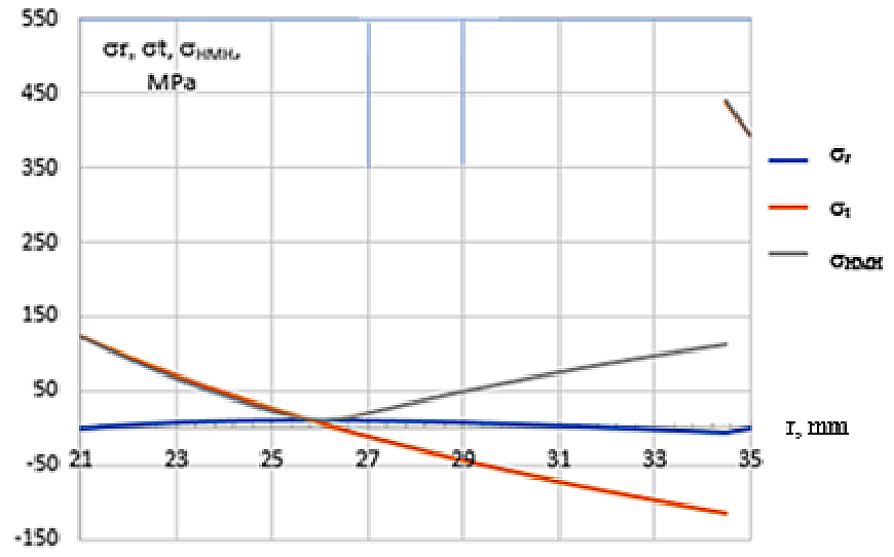

Fig. 5. Distributions of component stresses as a function of the radius $r$ when $\delta=0.5$

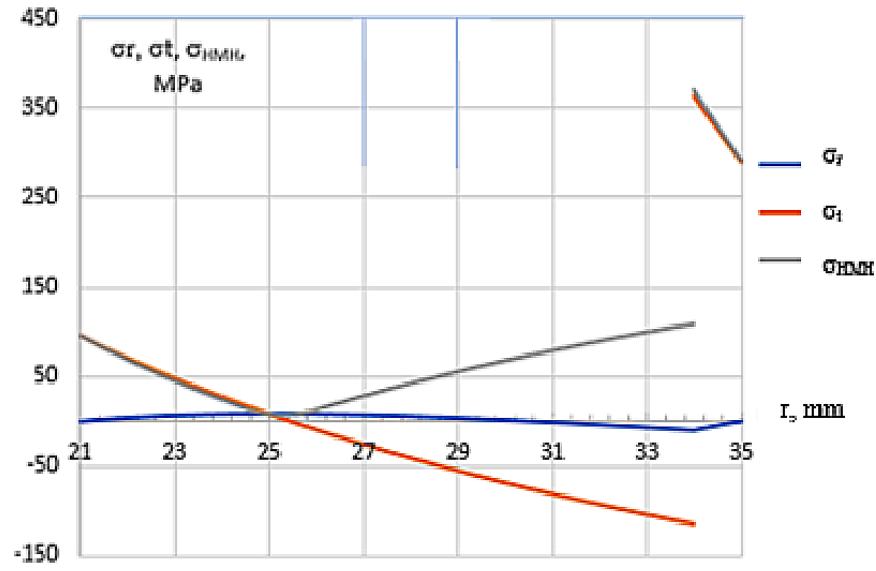

Fig. 6. Distributions of component stresses as a function of the radius $r$ when $\delta=1.0$

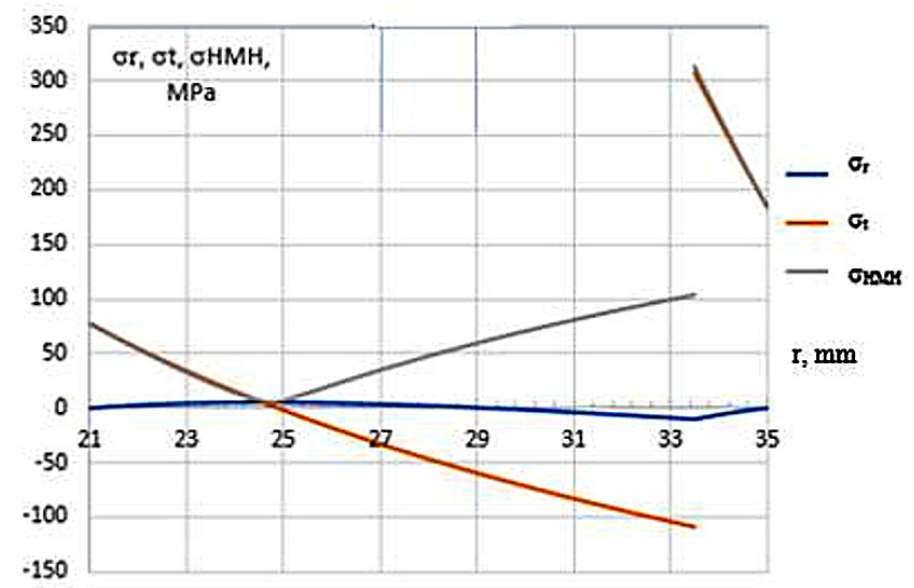

Fig. 7. Distributions of component stresses as a function of the radius $r$ when $\delta=1.5$

plunger was analysed. A selection method of the thickness of the ceramic coating deposited on the plunger was proposed. A selection criterion that the stresses in the ceramic coating should be lower than the tensile strength was assumed. The thickness of a technological outer layer should be selected based on the stress state analysis, which will delay the occurrence of thermal cracks in the outer layer and, thus, their propagation. It can also make a choice of the HPDC machine plunger material more reasonable by recognizing the operating conditions and thus provide longer life as well as reliability of plungers. 


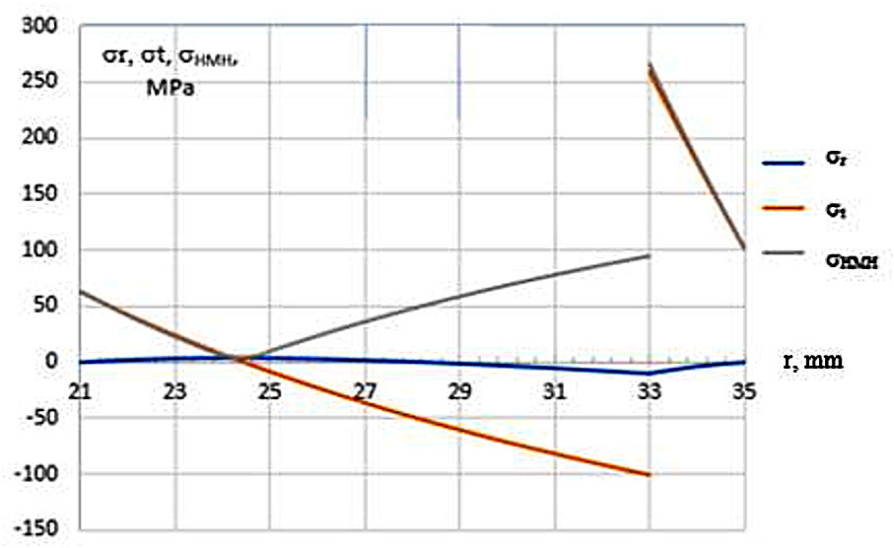

Fig. 8. Distributions of component stresses as a function of the radius $r$ when $\delta=2.0$

\section{Appendix I}

\section{Heat conduction through the cylindrical wall}

The Fourier equation referring to heat conduction in a steady-state through a single cylindrical wall can be written as (Fig. A1.1):

$$
\frac{Q^{*}}{L}=2 \pi \lambda \frac{T_{1}-T_{2}}{\ln \frac{r_{2}}{r_{1}}}
$$

where: $Q^{*}$ - heat conduction flux,

$L$ - cylindrical wall length,

$T_{1}, T_{2}$ - a temperature of the wall inner and outer surface, respectively (where the relationship $T_{1}>T_{2}$ holds),

$r_{1}, r_{2}$ - inner and outer radius of the cylindrical wall, respectively,

$\lambda_{1}$ - heat transfer coefficient.

By applying the equation for a one-layer cylindrical wall to a two-layer wall, (Fig. A1.2a), we obtain:

$$
\frac{Q^{*}}{L}=2 \pi \lambda_{1} \frac{T_{1}-T_{2}}{\ln \frac{r_{2}}{r_{1}}}=2 \pi \lambda_{2} \frac{T_{2}-T_{3}}{\ln \frac{r_{3}}{r_{2}}}
$$

Thus, the relationships hold:

$$
\frac{Q^{*}}{2 \pi L}=\frac{T_{1}-T_{3}}{\frac{1}{\lambda_{1}} \ln \frac{r_{2}}{r_{1}}+\frac{1}{\lambda_{2}} \ln \frac{r_{3}}{r_{2}}}=\frac{T_{1}-T_{2}}{\frac{1}{\lambda_{1}} \ln \frac{r_{2}}{r_{1}}}=\frac{T_{2}-T_{3}}{\frac{1}{\lambda_{2}} \ln \frac{r_{3}}{r_{2}}}
$$

From the above-mentioned relationships, it follows that temperature drops in individual layers of the wall are equal to:

$$
\frac{T_{2}-T_{3}}{T_{1}-T_{3}}=\frac{\frac{1}{\lambda_{2}} \ln \frac{r_{3}}{r_{2}}}{\frac{1}{\lambda_{1}} \ln \frac{r_{2}}{r_{1}}+\frac{1}{\lambda_{2}} \ln \frac{r_{3}}{r_{2}}}
$$

The relationships (A1.1)-(A1.4) hold when the heat flux is directed from the inside to the outside of the cylindrical wall (i.e., when $T_{1}>T_{2}-+$ Fig. A1.2a). In this study, however, the case when $T_{1}<T_{2}$ is considered. It means that the heat flux $Q$ is directed in an opposite direction (i.e., from the outer surface into the inner one) (Fig. A1.2b). Thus, having the above-mentioned in mind, equation (A1.4) takes a form:

$$
\frac{T_{2}-T_{1}}{T_{3}-T_{1}}=\frac{\frac{1}{\lambda_{1}} \ln \frac{r_{1}}{r_{2}}}{\frac{1}{\lambda_{1}} \ln \frac{r_{1}}{r_{2}}+\frac{1}{\lambda_{2}} \ln \frac{r_{2}}{r_{3}}}
$$

\section{Appendix II}

For the assumed axially symmetrical flat stress state in the thick-walled one-layer sleeve, the following relationships derived in [4] hold. In this Appendix, only basic formulas are quoted for clarity, namely:

- equation of heat conductivity in the stationary problem:

$$
\nabla^{2} T=\frac{1}{r} \frac{\partial}{\partial r}\left(r \frac{\partial T}{\partial r}\right)=0
$$

- equation of equilibrium:

$$
\frac{d \sigma_{r}}{d r}+\frac{\sigma_{r}-\sigma_{t}}{r}=0
$$




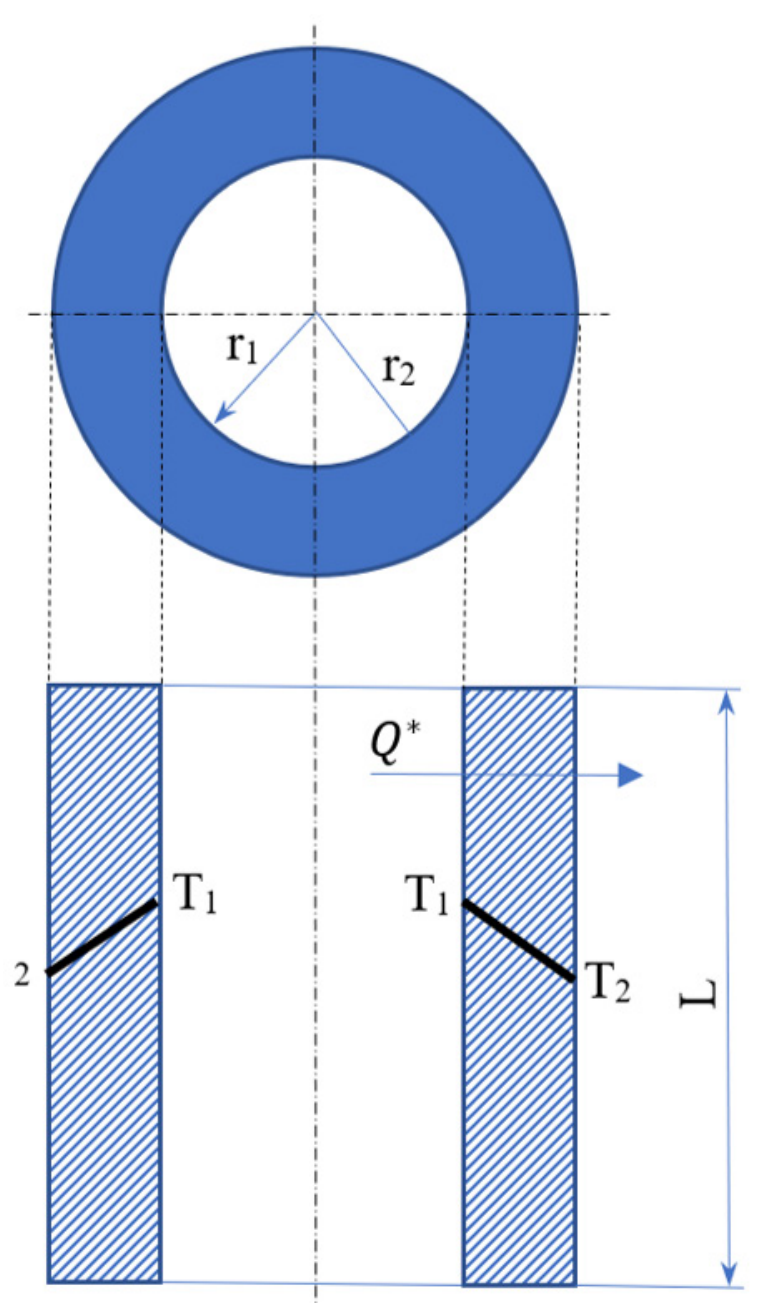

Fig. A1. Heat conduction through the cylindrical wall when $\mathrm{T}_{1}>\mathrm{T}_{2}$

- geometrical equations:

$$
\varepsilon_{r}=\frac{d u}{d r}, \quad \varepsilon_{t}=\frac{u}{r}
$$

Hooke's law

$$
\varepsilon_{r}-\alpha \Delta T=\frac{1}{E}\left[\sigma_{r}-v \sigma_{t}\right]
$$

where: $u$-radial displacement,

$\varepsilon_{r}$ - radial strains

$\varepsilon_{t}-$ circumferential strains,

$\sigma_{r}-$ radial stresses,

$\sigma_{t}-$ circumferential stresses,

$\Delta T=T(r)-T_{a}-$ temperature difference, $T(r=a)=T_{a}$ - temperature on the cylinder inner surface,

$T(r=b)=T_{b}$ - temperature of the cylinder outer surface, and, moreover: $T_{b}>T_{a}$,

$E$ - Young's modulus,

$v$ - Poisson's ratio,

$\alpha-$ linear expansion coefficient.
A solution to equation (A2.1) for the one-layer sleeve is written as $[\mathrm{A}]$ :

$$
T(r)=T_{a}+\left(T_{b}-T_{a}\right) \frac{\ln r / a}{\ln b / a}
$$

By substituting relations (A2.3) into (A2.2), we obtain an equation of equilibrium in displacements:

$$
\frac{d^{2} u}{d r^{2}}+\frac{1}{r} \frac{d u}{d r}-\frac{u}{r^{2}}=(1+v) \alpha \frac{d(\Delta T)}{d r}
$$

A solution to this equation takes a form:

$$
u=(1+v) \frac{\alpha}{r} \int_{a}^{r} \Delta \operatorname{Tr} d r+C r+\frac{D}{r}
$$

Taking into account the above mentioned in (A2.3) and (A2.4), the stress state components are expressed with the relationships:

$$
\begin{gathered}
\sigma_{r}=-\frac{E \alpha}{r^{2}} \int_{a}^{r} \Delta T r d r+ \\
+\frac{E}{1-v^{2}}\left[C(1+v)-D(1-v) \frac{1}{r^{2}}\right] \\
\sigma_{t}=\frac{E \alpha}{r^{2}} \int_{a}^{r} \Delta T r d r-E \alpha T+ \\
+\frac{E}{1-v^{2}}\left[C(1+v)+D(1-v) \frac{1}{r^{2}}\right]
\end{gathered}
$$

where the integration constants $C, D$ should be determined from the boundary conditions.

In (A2.7) and (A2.8), the following relationship holds:

$$
\begin{gathered}
\int_{a}^{r} \Delta T r d r=\int_{a}^{r}\left[T(r)-T_{a}\right] r d r=\int_{a}^{r} \\
\left(T_{b}-T_{a}\right) \frac{\ln r / a}{\ln b / a} r d r=\left.\frac{T_{b}-T_{a}}{\ln b / a}\left(\frac{r^{2}}{2} \ln \frac{r}{a}-\frac{r^{2}}{4}\right)\right|_{a} ^{r}
\end{gathered}
$$

\section{Appendix III}

Having the principal stress $\sigma_{r}, \sigma_{t}, \sigma_{z}$ determined (where $\sigma_{z}=0$ ), we can define the equivalent stresses within one of the two most recognized strength hypotheses for isotropic materials, i.e., the maximal shear stress theory $\tau_{\max }$ and the Huber-Mises-Hencky hypothesis $[1,3,10]$. The equivalent stresses should be equal to the allowable stresses in tension $k_{r}$ at most. 
a)

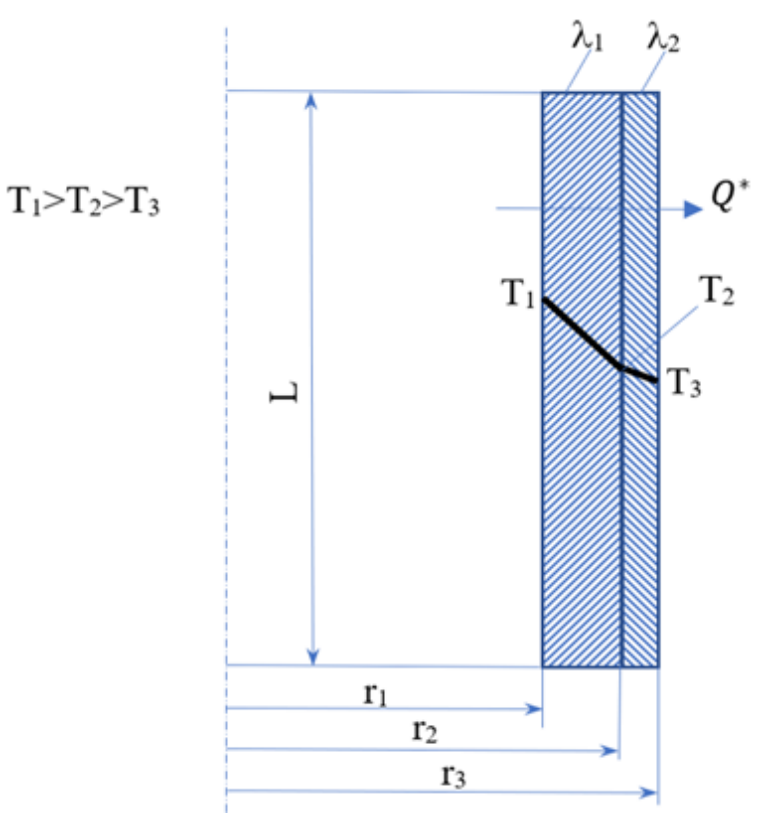

b)

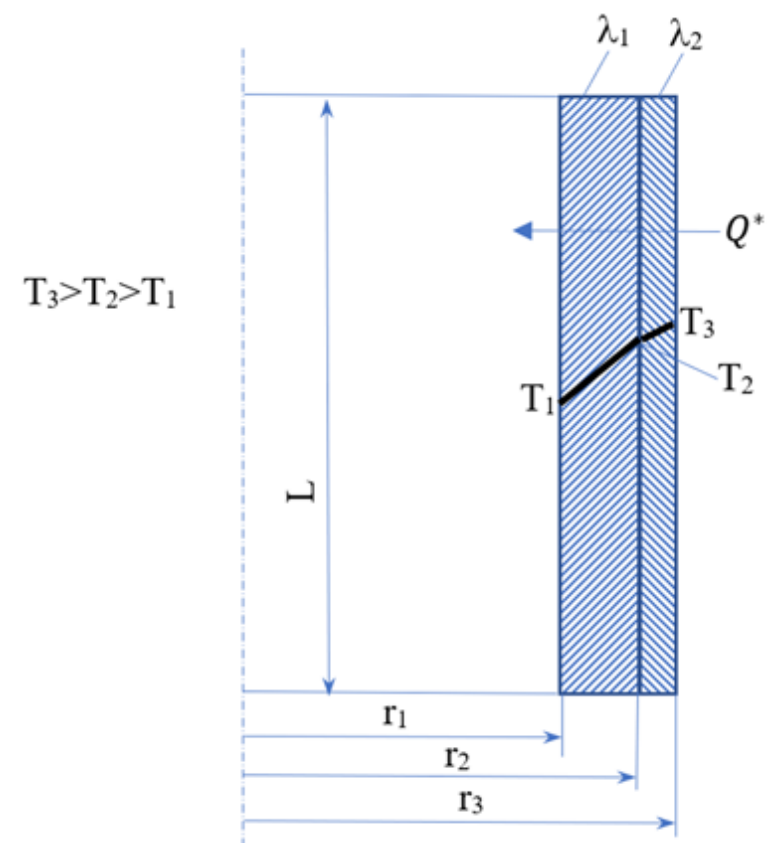

Fig. A2a. Heat conduction through the cylindrical two-layer wall when $T_{1}>T_{2}>T_{3}$

Fig. A2b. Heat conduction through the cylindrical wall when $\mathrm{T}_{1}<\mathrm{T}_{2}<\mathrm{T}_{3}$

In the study, the equivalent stresses were determined within the Huber-Mises-Hencky hypothesis (denoted as $\mathrm{HMH}$ ) $[1,3,10]$ :

$$
\begin{gathered}
\sigma_{\text {HMH }}=\left(\sigma_{\text {eqv }}\right)_{H M H}= \\
=\sqrt{\frac{1}{2}\left[\left(\sigma_{r}-\sigma_{t}\right)^{2}+\left(\sigma_{t}-\sigma_{z}\right)^{2}+\left(\sigma_{z}-\sigma_{r}\right)^{2}\right]} \leq k_{r}
\end{gathered}
$$

\section{REFERENCES}

1. Brzoska Z. Wytrzymałość materiałów. PWN, Warszawa 1983.

2. Derski W. Podstawy teorii sprężystości. PWN, Warszawa, 1965.

3. Dyląg Z., Jakubowicz A., Orłoś Z. Wytrzymałość materiałów. Wydawnictwo WNT, Warszawa 2013.

4. Jankowski J., Kołakowski D., Pisarek B.P. Analysis of mechanical and thermal stresses in an HPDC machine plunger. Advances Science and Technology Research Journal, 14(1), 2020, 209-223. https:// doi.org/10.12913/22998624/117724

5. Jankowski J., Kołakowski D., Pisarek B.P. Mechanical and thermal stresses in an HPDC machine plunger during the dosing and filling process. Advances Science and Technology Research Journal, 14(2), 2020, 1-12.
6. Kanlıkama B., Abuşoğlu A., Güzelbey I.H. Coupled thermoelastic analysis of thick-walled pressurized cylinders. International Journal of Energy and Power Engineering, 2, 2, 2013, 60-68.

7. Qi Shi M.S. Prediction of Thermal Distortion and Thermal Fatigue in Shot Sleeves. Dissertation, Advisor: Miller A. Presented in Partial Fulfillment of the Requirements for the Degree Doctor of Philosophy in the Graduate School of The Ohio State University, 2002, 3081965.pdf. Retrieved March 11, 2019, from https://etd.ohiolink.edu/!etd.send_fi le accession $=$ osu $1034967167 \&$ disposition $=$ inline

8. Silva E., Úbeda V. \& Fischer W. Shot Sleeves for Die Casting (Thermal Variations and its Consequences) Proceedings of the Foundry Congress: CONAF 2009, 22 to 25 September 2009 in Sao Paulo - SP, Microsoft Word - CONAF paper.doc. Retrieved March 11, 2019, from http://wfischer. com.br/en/files/CONAF-paper.pdf

9. Timoshenko S., Goodier J.N. Teoria sprężystości. Wydawnictwo Arkady, Warszawa 1962.

10. Walczak J. Wytrzymałość materiałów oraz podstawy teorii sprężystości i plastyczności. PWN, Warszawa-Kraków 1978.

11. http://www.matweb.com/search/datasheet.aspx?m atguid $=0654701067 \mathrm{~d} 147 \mathrm{e} 88 \mathrm{e} 8 \mathrm{a} 38 \mathrm{c} 646 \mathrm{dda} 195 \& \mathrm{c}$ $\mathrm{kck}=1$

12. https://www.azom.com/properties.aspx? ArticleID $=52$ 